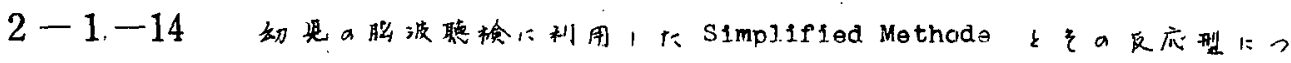
$\because \tau$.

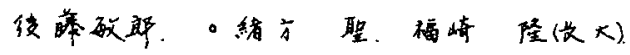

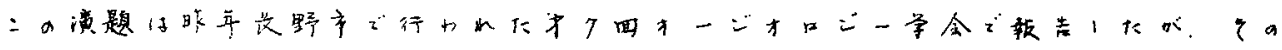

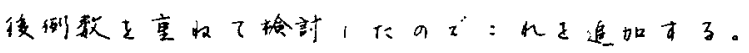

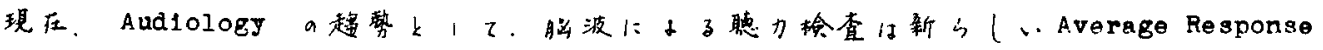

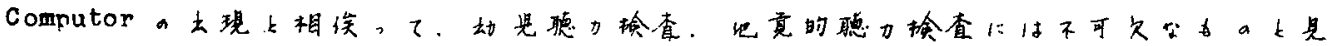
$x_{i} \leq れ つ$ ○る。

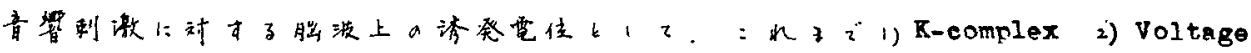
Sunpression 3) Spindel 4) Fast ave 5) Arousal response 等a反応が語めら

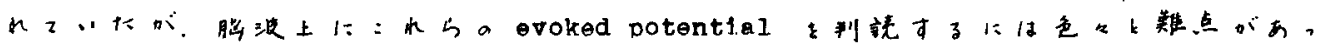

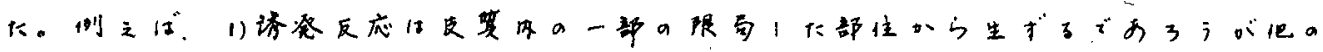

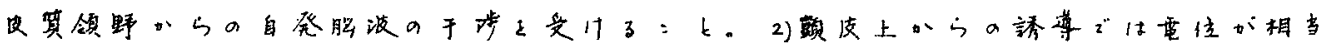

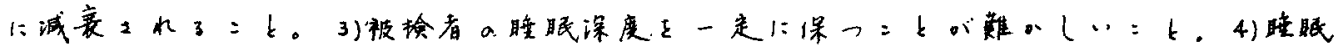

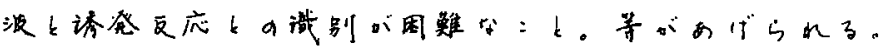

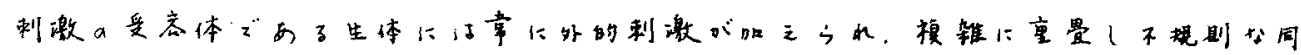

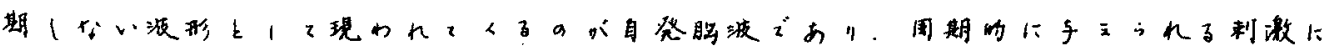

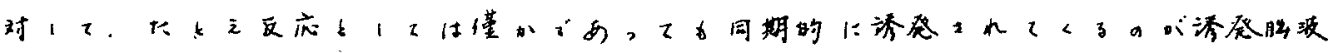

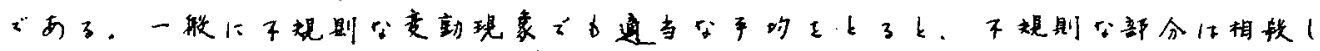

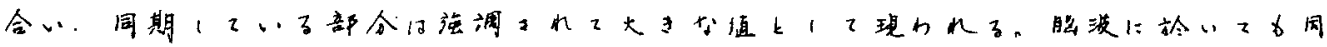

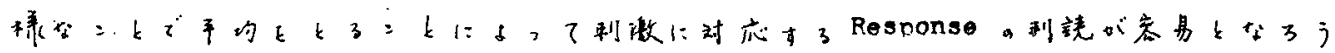

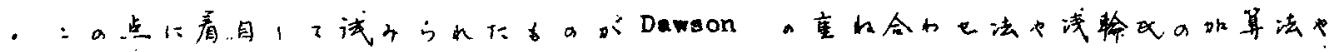

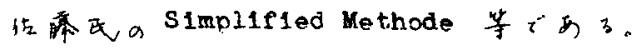

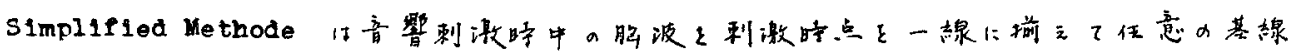

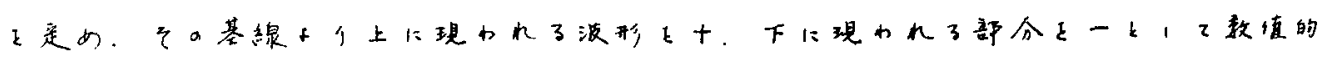

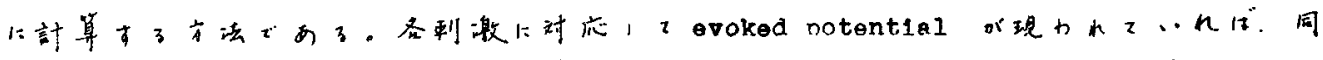

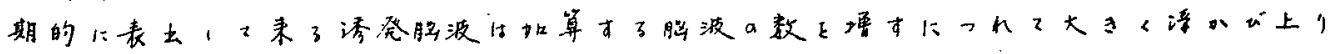

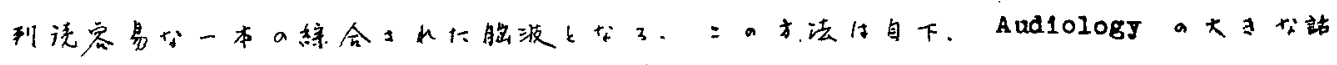
題 $4 x_{i}, 2 \cdots 3$ Average Resnonse Computora非算操

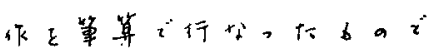
ある。

\title{
对象的当教参a Hearing
} speech Clinie 专乵么下奻

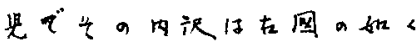

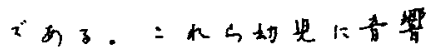

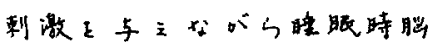

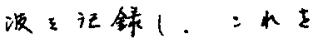

Diseases of the Tested Cnildren

$\begin{array}{lrrr}\text { Clinical tiagnosis } & \text { male } & \text { female } & \text { total } \\ \text { Congenital Deafness } & 2 I & \text { I3 } & 34 \\ \text { Hard of Hearling } & 7 & 6 & \text { II } \\ \text { Cerbral Palsy } & 4 & 4 & 8 \\ \text { Sudden Deafness } & 2 & 0 & 2 \\ \text { Cleft Palate } & 5 & 2 & 7 \\ \text { Audimutitas } & I & 0 & \text { I } \\ \text { Sperch Disorders } & 6 & 5 & \text { II } \\ \text { Epllepsy } & 0 & 2 & 2 \\ \text { Acquired Deafness } & 3 & 0 & 3 \\ \text { Atresia auris congenita } & I & 0 & I \\ \text { Others } & 2 & I & 3 \\ & & & \\ \text { Total } & 52 & 33 & 85\end{array}$

昭和 38 年 10 月 
Simplified Methode によ, Z分析 1 K。

命析成嘖

500. 1000. 2000. 4000. cps a 各国波教:

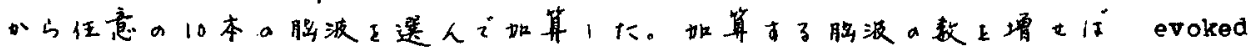

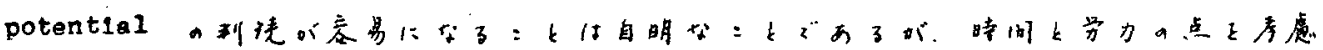

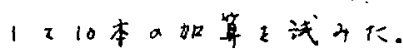

1)隊力正戈幼电の反应型

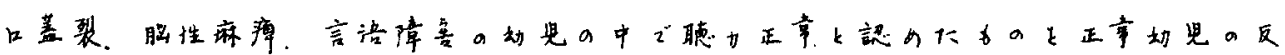

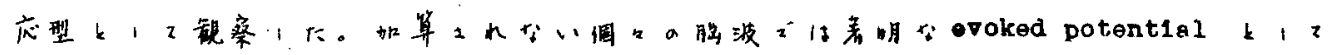

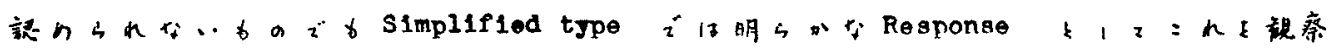

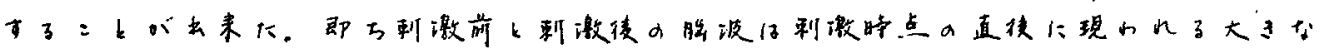

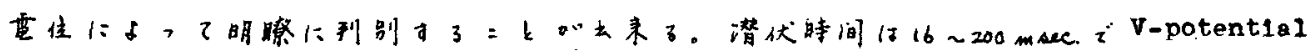

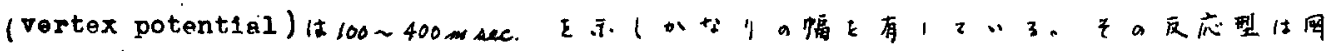
に示才如く5型に分数玉琙小た。

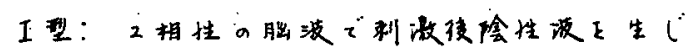

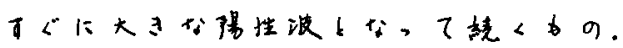

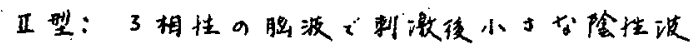

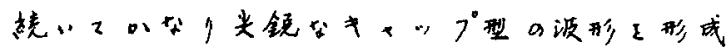
339 .

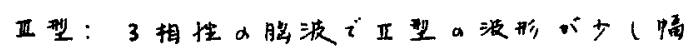
上增，た，

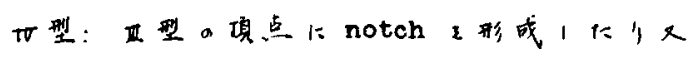
明方心三二峰状合裂、以

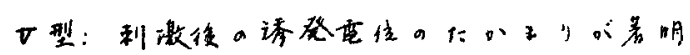

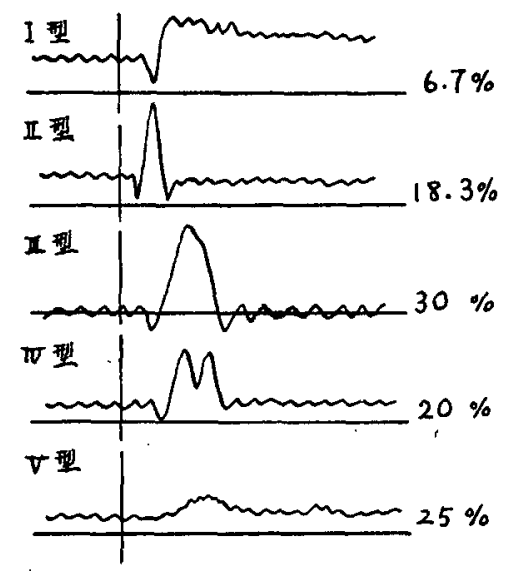

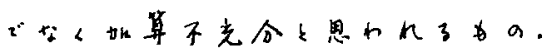

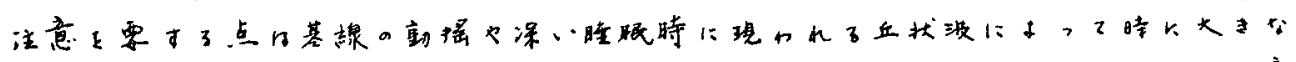

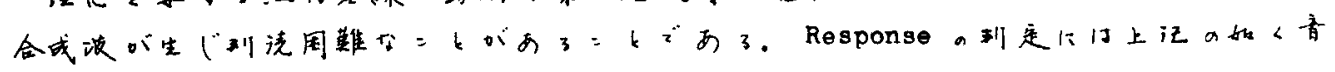

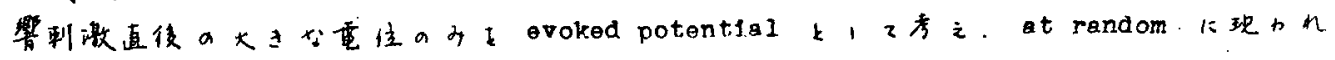
る菓位はKk之high roltage

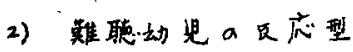

congenltal derfness, sudden desfness 等 a幼光

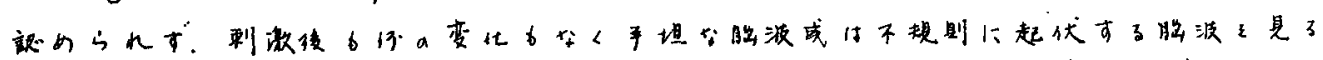

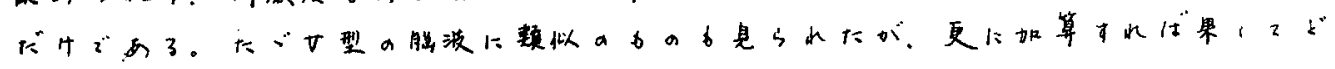

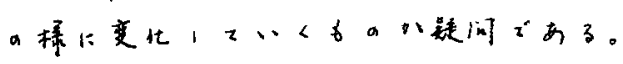

站

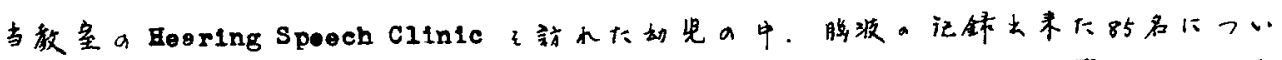

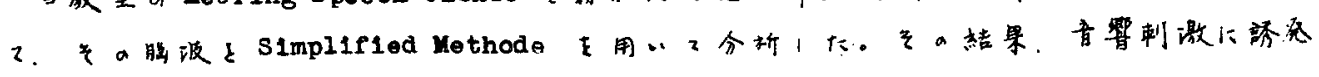

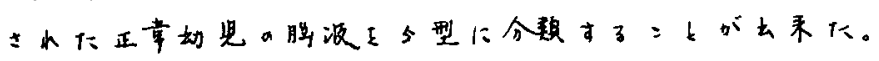

